\title{
USO PÚBLICO EM UNIDADE DE CONSERVAÇÃO: CAMINHOS APONTADOS NO PARQUE NATURAL MUNICIPAL DE NOVA IGUAÇU-RJ
}

\author{
Edileuza Dias de Queiroz \\ Universidade Federal Rural do Rio de Janeiro (UFRRJ), Instituto Multidisciplinar \\ Departamento de Geografia, Programa de Pós-Graduação em Geografia
} edileuzaqueiroz@gmail.com

\begin{abstract}
RESUMO
O uso público pode ser considerado um dos pilares fundamentais para conciliar a conservação ambiental com as atividades humanas, tendo em vista que a relação sociedade-natureza, de modo geral, tem representado um dos maiores e mais antigos desafios das sociedades humanas. Este trabalho, um dos frutos de uma tese de Doutorado, tem como objetivo apresentar caminhos possíveis para a consolidação do uso público em Unidades de Conservação, e teve como recorte espacial o Parque Natural Municipal de Nova Iguaçu/RJ. A metodologia, com abordagem qualitativa e ancorada no método fenomenológico, é baseada na análise das ações elaboradas e/ou implementadas no decorrer da pesquisa, onde procurou-se analisar atividades de ensino, pesquisa e extensão. A pesquisa revelou, dentre outros aspectos, a importância da parceria, principalmente da Universidade e seu tripé fundante, para que as Unidades de Conservação continuem a existir e cumpram seu papel social e ambiental. Espera-se contribuir com reflexões para que Parques com características semelhantes consigam, diante de suas condições, efetivar o uso público, tão essencial para o seu papel na sociedade. Ressalte-se que os caminhos que podem levar à essa consolidação exigem esforços tanto do poder público quanto da sociedade civil.
\end{abstract}

Palavras-chave: Unidades de Conservação. Uso Público. Parque Natural Municipal de Nova Iguaçu.

\section{PUBLIC USE IN PROTECTION AREA: PATHS POINTED IN NOVA IGUAÇU MUNICIPAL NATURAL PARK-RJ}

\begin{abstract}
Public use can be considered one of the fundamental cornerstones when balancing environmental conservation and human activities, considering that the relationship societynature, in general, represents one of the biggest and oldest challenges for human societies . This paper, one of the products of a Doctorate thesis, has as its goal to present possible paths for the consolidation of public use in Protection Areas. The delimitated space for analysis was the Nova Iguaçu Municipal Natural Park (RJ). The methodology employed, in a qualitative approach and anchored in a phenomenological method, is based on the analysis of the actions elaborated and/or implemented throughout the research, where it sought to analyze teaching, research, and university extension activities. Among other aspects, the research revealed the partnership's importance, primarily of the University and its founding tripod, in such a way that Protection Areas can continue to exist and to fulfill their social and environmental roles. It is hoped that this article will contribute to further considerations so that similar parks can, according to its own conditions, make public use effective, vis-à-vis its relevance to its role in society. It must be emphasized that the ways in which this consolidation can be delivered demands efforts from public authorities as well as civil society.
\end{abstract}

Keywords: Protection Areas. Public Use. Nova Iguaçu Municipal Natural Park.

\section{INTRODUÇÃO}

A reflexão acerca das Unidades de Conservação (UC) nos remete à questão do uso público, que Pimentel (2013, p. 30) conceitua como "o uso indireto dos recursos ambientais se dá sob as diferentes formas de visitação de uma unidade de conservação e, portanto, deve sempre ser orientado pelos preceitos da sustentabilidade e mitigação de seus impactos". O Sistema Nacional de Unidades de Conservação - SNUC - (Lei 9.985 de 18/07/2000), classifica as UC em 12 categorias, que são divididas em 2 grupos, a saber: 1) Proteção Integral; 2) Uso Sustentável. As UC da categoria de Proteção Integral, com uso mais restritivo, são) Estação Ecológica, Reserva Biológica, Parque

$\begin{array}{lllll}\text { Caminhos de Geografia } & \text { Uberlândia-MG } & \text { v. 22, n. } 82 & \text { ago./2021 } & \text { p. 89-101 }\end{array}$


Nacional, Monumento Natural, Refúgio da Vida Silvestre. Dentre estas, duas permitem o uso público, embora sujeito a normas e regras, Parque Nacional e Monumento Natural.

Dentre as UC que permitem o uso público - incluindo a categoria Parque - muitas não têm estrutura para que o uso público seja eficiente, no tocante à conservação da biodiversidade e satisfação dos usuários com o menor impacto possível. O termo "uso público" é abordado, neste trabalho, como uma forma de utilização das UC, por meio de visitação, independentemente da motivação (contemplação, recreação, pesquisa, Educação Ambiental, esporte, observação de aves, entre outros) ou do segmento de turismo (ecoturismo, turismo de aventura, entre outros). (Rodrigues, Irving, Drummond, 2010).

Consideramos que o uso público eficiente é primordial para a gestão dos Parques, pois é através da consolidação de um uso racional, seguro e com poucos impactos negativos que a gestão terá possibilidades de implementar as ações contidas no plano de manejo. "A gestão ambiental faz parte de um processo mais amplo de gestão do território, aspecto para o qual ainda não se deu a devida relevância" (CUNHA, COELHO, 2007, p. 43).

Os parques possuem um papel fundamental na inserção social e no desenvolvimento do uso público nessas áreas protegidas, uma vez que, é a categoria mais conhecida entre o público, e também com os maiores níveis de visitação. No entanto, existem muitos desafios a serem superados, onde haja satisf ação do usuário com a conservação do lugar. É importante o desenvolvimento de atividades de inclusão social que tenham como base os processos formativo e educativo, pois, as "marcas" deixadas pelos usuários muitas vezes são de alto nível de degradação.

Ressalte-se aqui, a importância socioambiental dos parques, que se destaca pelo valor educacional, científico e recreativo das áreas, pelos benefícios proporcionados pelo ecossistema às comunidad es, importância estética e presença de plantas e animais, muitas vezes em avançado processo de extinção. Vallejo faz um diálogo entre os parques, as questões ambientais e o uso público, ressaltando a responsabilidade governamental. Segundo este autor:

Os parques são espaços onde as questões da conservação ambiental e do uso público mais se aproximam. Se os governos não assumem suas responsabilidades diante deles, aumentam os conflitos e as possibilidades de rejeição territorial, com efeitos contrários aos objetivos dos próprios parques. (VALLEJO, 2005, p. 14)

Entretanto, apesar da importância social e ambiental, estes territórios não têm tido a devida atenção, carecendo de recursos financeiros e humanos, o que dificulta o trabalho da gestão, pois, um dos seus grandes desafios é envolver as pessoas e as instituições para que, coletivamente, possam construir caminhos que levem à consolidação do uso público, uma vez que sem o estreitamento das relações, o trabalho tende a ser mais difícil e até conflituoso.

Trazer as pessoas para dentro dos Parques é um grande desafio, porque isso exige, principalmente, atividades formativas, pessoal capacitado e em quantitativo suficiente para atender os usuáriosvisitantes, infraestrutura e logística adequadas, atendimento ao plano de manejo. Entretanto, há um ator com um grande potencial para que as ações sejam desenvolvidas: o poder público. É preciso vontade política, conforme afirma Dourojeanni (2002, p. 348), que a define como "(...) uma decisão pública de 'pagar o custo' de criar e manejar um parque", esses custos são tanto políticos quanto econômicos. Desta forma, um dos principais problemas que aflige diretamente os gestores de parques é a insuficiência econômica. Diante desse cenário é preciso encontrar novos caminhos para que a UC continue a existir, a prestar serviços com uma margem de qualidade satisfatória, apesar das grandes dificuldades. No decorrer deste texto serão apresentadas algumas possibilidades que foram planejadas e postas em ação.

Assim, o objetivo deste texto é apresentar caminhos possíveis para a consolidação do uso público em Unidades de Conservação, e teve como recorte espacial o Parque Natural Municipal de Nova Iguaçu/RJ. É oriundo do recorte de uma pesquisa de doutorado se debruçou no planejamento, desenvolvimento e análises de atividades na referida UC. Neste sentido, tais atividades são apresentadas com o intuito de subsidiar novas atividades e pesquisas em espaços legalmente protegidos, especialmente a categoria Parque.

\section{METODOOGIA}

O PNMNI localiza-se na Baixada Fluminense, mais precisando em territórios dos municípios de Nova Iguaçu e Mesquita. Mesmo com a denominação "Nova Iguaçu", a UC está inserida nesses dois municípios, pois, sua criação ocorreu em 1998, através do Decreto 6.001 de 05 de junho de desse ano, porém, em 1999 o município de Mesquita foi emancipado da administração da cidade vizinha, Nova lguaçu, que é responsável pela administração da UC.

Caminhos de Geografia $\quad$ Uberlândia-MG $\quad$ v. 22, n. $82 \quad$ ago./2021 $\quad$ p. 89-101 Página 90


Ocupando uma área de 1.100 hectares no maciço Gericinó-Mendanha, sua delimitação é feita pela Serra de Madureira, na vertente voltada para os municípios de Nova lguaçu e Mesquita, e pela Serra do Mendanha, na vertente do município do Rio de Janeiro. A variação altimétrica oscila em torno da cota $150 \mathrm{~m}$, onde está situada a entrada principal e a cota $956 \mathrm{~m}$, onde se localiza o marco sudoeste, nas proximidades do pico Gericinó-Mendanha. Segundo Duarte (2010, p. 103), foi “(...) a possibilidade de ocupação e destruição total dos remanescentes florestais através do projeto habitacional do Governo Estadual fez com que o município de Nova Iguaçu tomasse a atitude de enfim tornar a área uma unidade de proteção integral".

No primeiro momento da pesquisa de Doutorado - da qual o presente texto é oriundo -, foi realizada a pesquisa documental, que se deu a partir da leitura e análise do plano de manejo do PNMNI, bem como as atas do conselho consultivo ${ }^{1}$, entre os anos de 2014 a 2018, documentos gentilmente cedidos pelo gestor do Parque. Isto foi fundamental para a compreensão das dificuldades da implementação de um uso público onde as atividades realizadas pelos usuários-visitantes e a conservação da biodiversidade estivessem em consonância.

Dando prosseguimento, no segundo semestre de 2015, foram realizados trabalhos de campo para observação, conversas informais com a equipe gestora e com os usuários-visitantes, participação nas reuniões bimestrais do conselho consultivo. A partir do ano de 2016, essas incursões foram realizadas semanalmente, sempre nos finais de semana. Houve necessidade de estar na UC para captar as demandas referentes ao uso público.

No período de setembro de 2016 a fevereiro de 2017, foi desenvolvido um projeto piloto de voluntariado, divulgado através das redes sociais. Esta divulgação teve como meta sensibilizar a comunidade do entorno, visitantes e também o público do Instituto Multidisciplinar da Universidade Federal Rural do Rio de Janeiro (IM-UFRRJ), pois esta é a única instituição pública de ensino superior localizada no município de Nova lguaçu, nas proximidades do Parque. E também onde a autora da tese de doutorado exerce suas atividades docentes.

O projeto acima citado teve como objetivo sensibilizar diferentes atores que fazem algum uso do Parque para uma interação com o lugar, tendo em vista que o voluntariado possibilita o envolvimento dos participantes. Assim, no dia 09 de setembro de 2016, na sede do PNMNI teve início do Programa de Voluntariado, que foi subdividido em quatro equipes, conforme descritas abaixo, e para cada uma destas foi eleito um coordenador. Desta forma, as equipes compostas foram:

1) Monitoramento e orientação dos usuários-visitantes (campanhas educativas), composta por 5 integrantes - com o objetivo de realizar campanhas educativas com os frequentadores do Parque nos dias de maior afluência de público, visando preservar o ecossistema, bem como estimular a reflexão/conscientização sobre a questão ambiental. Buscando também incentivar frequentadores a serem agentes multiplicadores a fim de disseminar atitudes de conservação dos ecossistemas;

2) Educação Ambiental, composta por 5 integrantes - com o objetivo de desenvolver atividades de Educação Ambiental, mais especificamente com o público escolar. O coordenador dessa equipe, aluno de Geografia do IM- UFRRJ, desenvolveu parte de seu projeto de Iniciação Científica em uma escola localizada na zona de amortecimento do Parque.

3) Mutirão, composta por 25 integrantes, sendo 11 somente dessa equipe e 14 das demais equipes - com o objetivo de realizar atividades variadas, principalmente, manutenção das trilhas, abordagem de sensibilização com moradores do entorno e com os usuários-visitantes, mutirão de limpeza nas margens do rio dona Eugênia e afluentes; e coleta de resíduos. Caminhadas até a rampa de vôo livre para sensibilizar os moradores do entorno em relação às queimadas, problema constante na vertente norte da UC.

4) Apoio à Gestão, composta por 4 integrantes - o objetivo foi apoiar à administração do Parque; manutenção do acervo de pesquisa bem como o mapeamento destas; busca de parcerias. Esta equipe teve algumas dificuldades, tais como a inexistência dos exemplares das pesquisas realizadas e falta de parceria de empresas do município para apoiar o projeto.

Apesar da divisão do grupo em equipes, todos os 25 voluntários estavam juntos nos dias de mutirão (1 vez por mês), para troca de experiências e traçar novas estratégias para fortalecimento do projeto.

${ }^{1}$ O Conselho Consultivo é previsto no Sistema Nacional de Unidades de Conservação (SNUC) para as UC de proteção integral, importante instrumento de inclusão social e gestão democrática. O Conselho Consultivo do PNMNI se reúne a cada dois meses, no entanto, tem se observado um esvaziamento tanto da composição quanto das questões que são tratadas. 
Nesses encontros os coordenadores das equipes faziam uma exposição das atividades desenvolvidas.

Ressalte-se que esse Projeto Piloto de Voluntariado foi elaborado e implementado a partir do que foi observado nos trabalhos de campo semanais, nos diálogos informais com a moradores do entorno, usuários-visitantes e equipe gestora; participação nas reuniões do conselho consultivo e a leitura e análise do Plano de Manejo. Esses caminhos metodológicos também mostraram que, a parceria principalmente com a Universidade - é extremamente importante, pois, em um espaço legalmente protegido como os Parques, o tripé universitário (ensino, pesquisa e extensão) de fato acontece. Isso foi observado durante os anos de pesquisa no PNMNI, conforme pode ser verificado a seguir.

\section{RESULTADOS}

A seguir, serão expostas e analisadas atividades de extensão, pesquisa e ensino desenvolvidas no PNMNI durante a realização da pesquisa de Doutorado. Acredita-se que a parceria entre a parte gestora e a universidade pode representar um dos caminhos para nortear algumas reflexões e ações que contribuam, de fato, tanto para o fortalecimento da gestão do uso público, quanto para a inserção social nos Parques. A formação e a informação são fatores fundamentais para que isso ocorra, pois, o acesso e o domínio do conhecimento representam veículos de poder, notadamente ao legitimar práticas e discursos (MORAES, 2005).

Pimentel (2013) aponta várias atividades que contribuem para a consolidação desse uso público através das parcerias, principalmente, com as universidades. Isto foi confirmado com a pesquisa, algumas instituições universitárias, principalmente o IM-UFRRJ e a Universidade Federal Fluminense (UFF) vêm realizando atividades de ensino, pesquisa e extensão no PNMNI, com resultados bem expressivos, com contribuições importantes para o uso público e também para a população do entorno.

\section{Atividades Extensionistas}

Estas atividades representam um quantitativo bem significativo no PNMNI, dentre as quais, foi escolhido para análise neste texto o Programa-Piloto de Voluntariado no PNMNI, pois, mesmo após o término da pesquisa de Doutorado o Programa de Voluntariado continua acontecendo, atualmente realizando atividades mutirão de limpeza, replantio de mudas de plantas nativas, entre outras atividades

A partir da leitura da realidade através da vivência in loco e da leitura de outros trabalhos (AMADOR; PALMA, 2013; MINISTÉRIO DO MEIO AMBIENTE, 2002, entre outros) e na entrevista com o gestor, foi proposto e implementado o "Projeto-Piloto de Voluntariado", iniciado em setembro de 2016. O voluntariado é uma prática bastante comum em UC de países desenvolvidos, Moniz e Günther (2011, p. 117), afirmam que "(...) o voluntariado ambiental encontra-se entre as iniciativas que se desenvolvem de forma altruísta, de modo livre e sem expectativa de lucros, com tarefas diretas para a melhoria ambiental e conservação dos recursos naturais". Além disso, há desenvolvimento de transformação pessoal e social, contribuindo tanto para a formação identitária de pertencimento quanto para a possibilidade de construção de uma sociedade mais igualitária e comprometida ambientalmente.

Ressaltamos que o entendimento de voluntariado proposto pelo projeto-piloto para esta pesquisa está embasado no voluntariado orgânico, entendido como "(...) participação politizada, comprometida, ativa e beneficente das pessoas que desenvolvem o serviço voluntário na construção das condições necessárias à democratização efetiva do Estado" (SELLI; GARRAFA, 2005, p. 473). Isto difere do modelo assistencialista e não há intenção de substituir os funcionários pelos voluntários e nem a transferência das responsabilidades do órgão público responsável pela gestão territorial.

Assim, seguindo as premissas do voluntariado orgânico, o grupo de voluntários que compôs o projeto-piloto foi formado por alunos dos cursos de Geografia, Turismo e Pedagogia do IM-UFRRJ. A chamada foi feita através das redes sociais e exposta nos murais do campus. Os funcionários do Parque também se juntaram ao grupo, foi um trabalho coletivo muito interessante.

Na figura 1, a seguir, podemos observar um grupo de voluntários preenchendo a ficha de cadastro para, em seguida, formarem as equipes (como citadas anteriormente) de acordo com suas afinidades. Isso foi muito importante porque resultou em interesses por temas de pesquisas de Iniciação Científica, Monografias e Dissertação de Mestrado.

$\begin{array}{lllll}\text { Caminhos de Geografia } & \text { Uberlândia-MG } & \text { v. 22, n. } 82 & \text { ago./2021 } & \text { p. 89-101 }\end{array}$


Figura 1 - Voluntários preenchendo a ficha de cadastro.

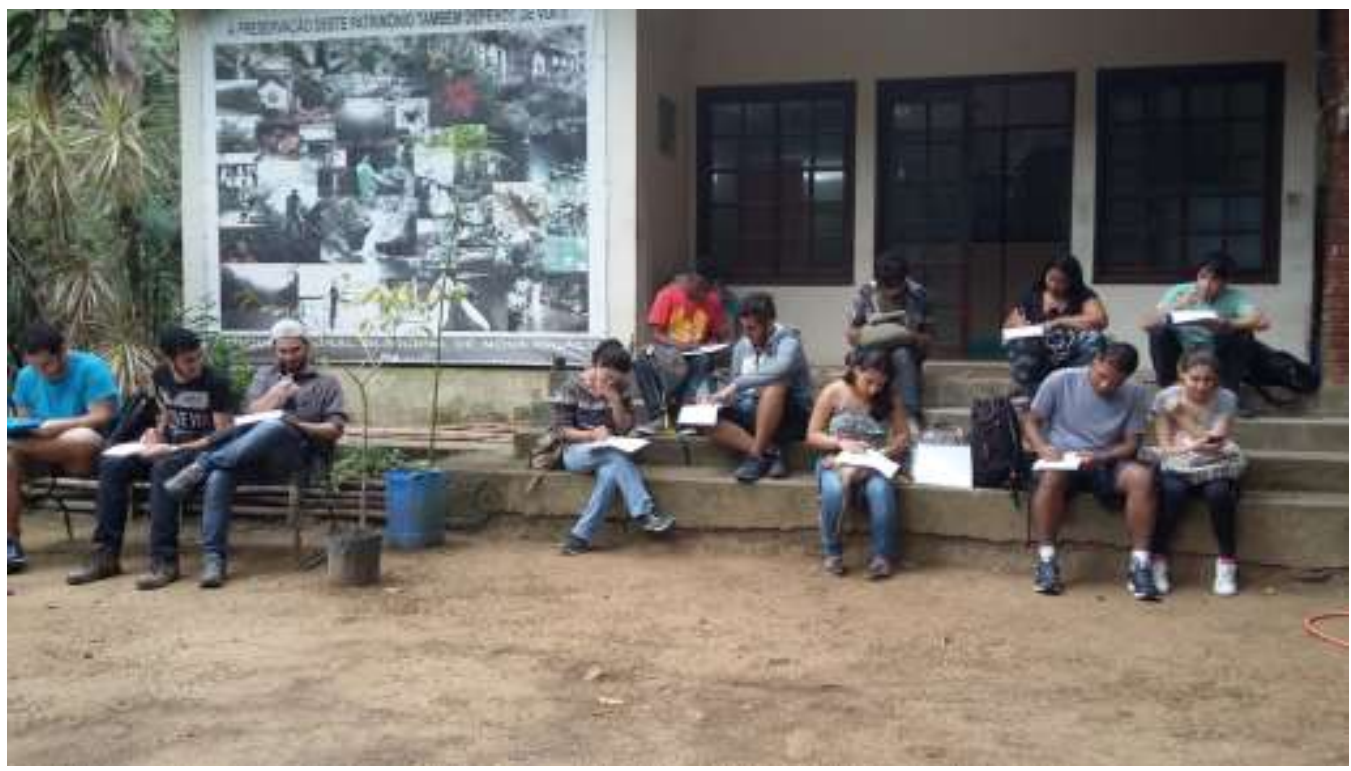

Fonte - a autora, 2016.

Para cada uma dessas equipes foi eleito um coordenador, objetivando dividir as tarefas específicas. Cada final de semana uma equipe estava do Parque e uma vez por mês todos estavam juntos para avaliar as ações e realizar o mutirão. Consideramos que foi um aprendizado significativo para os voluntários, bem como para a equipe gestora.

Apesar dos esforços da equipe de "Apoio à gestão", nenhuma parceria com empresas foi realizada. Duas empresas de transportes foram contactadas duas vezes; foram realizadas duas visitas a três papelarias e a duas farmácias, e nenhum dos representantes desses estabelecimentos demonstrou interesse em colaborar com a UC. Também avaliamos que a Prefeitura de Nova Iguaçu não empreendeu esforços suficientes para realizar a contrapartida, como o transporte e a alimentação para os voluntários, por exemplo.

Figura 2 - Curso de Educação Ambiental em Unidades de Conservação.

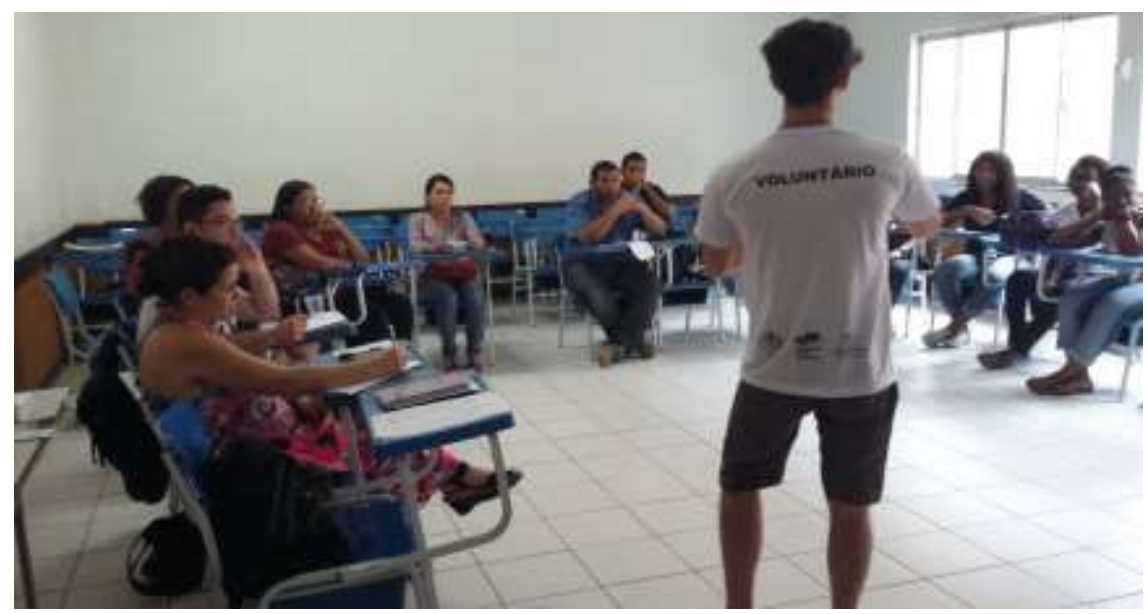

Fonte - a autora, 2016.

A figura 2 acima, se refere ao minicurso que foi realizado pela equipe de Educação Ambiental, visando salientar a importância dessa vertente educacional em UC, o público -alvo foi composto por professores da educação básica e licenciandos. Essa atividade teve a duração de dois dias, um deles

Caminhos de Geografia $\quad$ Uberlândia-MG $\quad$ v. 22, n. $82 \quad$ ago./2021 $\quad$ p. 89-101 Página 93


no IM-UFRRJ com uma turma na parte da manhã e outra na parte da tarde do dia 25 de novembro de 2016, com uma carga horária de 10 horas. Com a colaboração dos professores Cristiane Cardoso e Mauro Guimarães, ambos do Curso de Geografia do IM-UFRRJ; o outro encontro aconteceu no Parque, dia 26 de novembro de 2016, no período de 09:00 às 13:00. Nesse dia com a participação de Flávia Lopes Oliveira, doutora pelo Programa de Pós Graduação em Geografia da Universidade do Estado do Rio de Janeiro (PPGEO/UERJ), que realizou um estudo sobre geoconservação no Parque. $\mathrm{O}$ curso terminou com um banho de cachoeira e um lanche coletivo.

Além dessa atividade, a equipe de Educação Ambiental também realizou atividades em uma escola próxima ao Parque, Escola Municipal Ondina Couto. Por conta do Programa de Voluntariado, o aluno Gabriel dos Santos Martins realizou nessa escola seu projeto de Iniciação Científica intitulado "Educação Ambiental no Parque: uma proposta para inserção da dimensão socioambiental através do trabalho de campo". Esta pesquisa de Iniciação Científica gerou um artigo publicado na revista APPAI - EDUCAR, ano 19, no 104, 2017. Houve um trabalho publicado nos Anais do V Congresso Nacional de Educação Ambiental \& VII Encontro Nordestino de Biogeografia, sediado na Universidade Federal da Paraíba, no mês de outubro de 2017. Outro fruto oriundo dessa equipe foi a publicação do artigo "A construção da felicidade no trabalho voluntariado em Educação Ambiental no Parque Natural Municipal de Nova Iguaçu-RJ", cujos autores são Queiroz, E.D.; Martins, G.S., Revista Hipótese, volume 4, número 3, 2018.

A equipe de mutirão realizou três atividades de manejo de trilha, tendo em vista que é uma demanda por conta, principalmente, dos acessos aos poços para os banhos. Também organizou as salas da sede administrativa, dialogou com usuários-visitantes, visitou moradores. Na figura 3 , a seguir, podemos verificar o antes e o depois de um mutirão de manejo de trilhas no Poço da Natureza, isto facilitou o acesso de usuários-visitantes a esse poço. Essa equipe realizou mais dois trabalhos semelhantes a esse em outras trilhas do Parque.

Figura 3 - Acesso ao poço da natureza - antes e após o manejo.
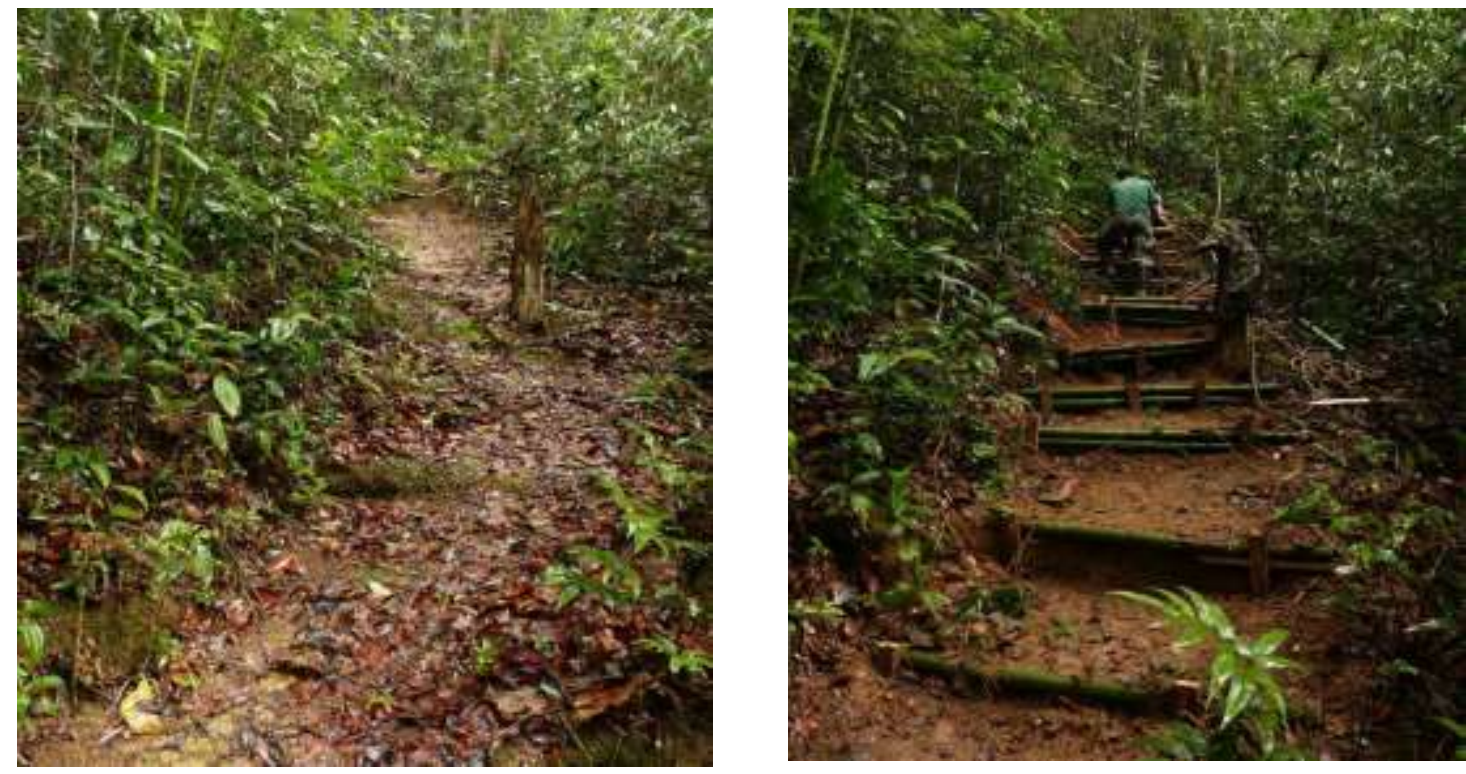

Fonte - Edgar Martins, 2016.

Muitas atividades foram realizadas ao longo do período planejado e, conforme programado, em fevereiro de 2017 o Projeto-Piloto foi encerrado, com a certeza de que o voluntariado representa um caminho interessante e deve ser estimulado. No evento que marcou o encerramento do projeto-piloto, houve o anúncio por parte de alunos do IM-UFRRJ e de funcionários do Parque, de que o programa

$\begin{array}{lllll}\text { Caminhos de Geografia } & \text { Uberlândia-MG } & \text { v. 22, n. } 82 & \text { ago./2021 } & \text { p. 89-101 Página } 94\end{array}$


iria continuar. Atualmente, o Programa de Voluntariado está ativo e se reúne uma vez por mês, realizando trabalhos nas duas vertentes (norte e sul), alertando os usuários-visitantes acerca dos cuidados para com a UC, atividades de sensibilização dos moradores sobre os riscos de incêndios, entre outras.

No mês de agosto de 2017, devido à muitas ocorrências de incêndios na vertente norte, voluntários se organizaram para conversar com a população sobre esse problema. Na figura 4, temos o panfleto confeccionado e entregue pelos voluntários em dia de mutirão.

Figura 4 - Panfleto entregue para a população e visitantes na vertente norte do PNMNI.

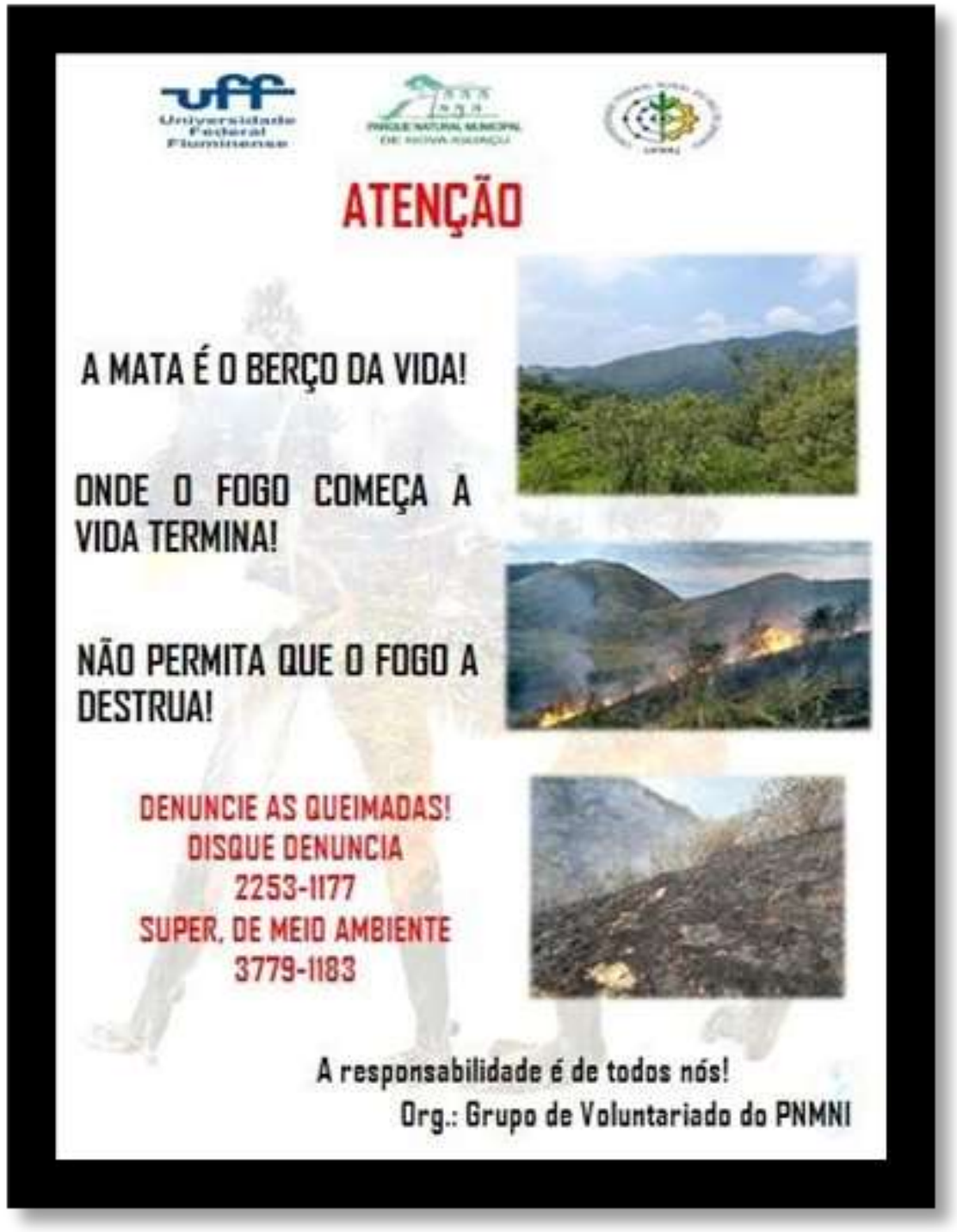

Fonte - Queiroz, 2018.

Ressalte-se a participação ef etiva do gestor e sua equipe nos mutirões, acredita-se que isso seja fundamental para que o programa continue a existir, pois o trabalho voluntário não substitui as obrigações do poder público e este deveria incentivar e apoiar, oferecendo transporte, alimentação e o material necessário para que o trabalho seja realizado, como forma de motivação dos participantes e continuidade do trabalho de seus membros. O apoio e incentivo da equipe gestora são fundamentais num programa de voluntariado.

Em setembro de 2017, uma reportagem do jornal O Dia fez o registro abaixo e, na figura 5, observamos um voluntário (de camisa branca) fazendo o monitoramento dos visitantes.

Caminhos de Geografia $\quad$ Uberlândia-MG $\quad$ v. 22, n. $82 \quad$ ago./2021 $\quad$ p. 89-101 Página 95


A

Baixada Fluminense entrou para o roteiro turístico ecológico do estado, chamando mais atençăo para suas belezas naturais. Esta é a aposta do projeto Baixada Verde que pode pode mudar a imagem da regiâo, conhecida pelos proble-
mas sociais. Um dos pontos mas sociais. Um dos pontos de Nova Iguaçu, que preserva floresta que corresponde a um terço da Mata Atlântica que restou no estado.

Rafael Souza, 30, de Mesquita, visitou o parque pela primeira vez e aprovou. "Ouvia falar, mas nunca tinha vindo. Estou amando tudo que estou vendo".

São 1.100 hectares de área preservada, o equivalente a noo campos de futebol, com una grande diversidade da faunae da flora da Mata Atlântica Osvisitantespodem aindase refresear nos Inlagos liberados para banho. Quemquer aventura tem ainda sete trilhas, duas áreas para rappel e escalad a mo rampa de voo livre e de Nova Iguact

Para Edgar Martins, diretor do parque, este é um grande

\section{Nova rota: Baixada Verde}

Projeto aposta no potencial turístico do Parque Municipal de Nova Iguaçu

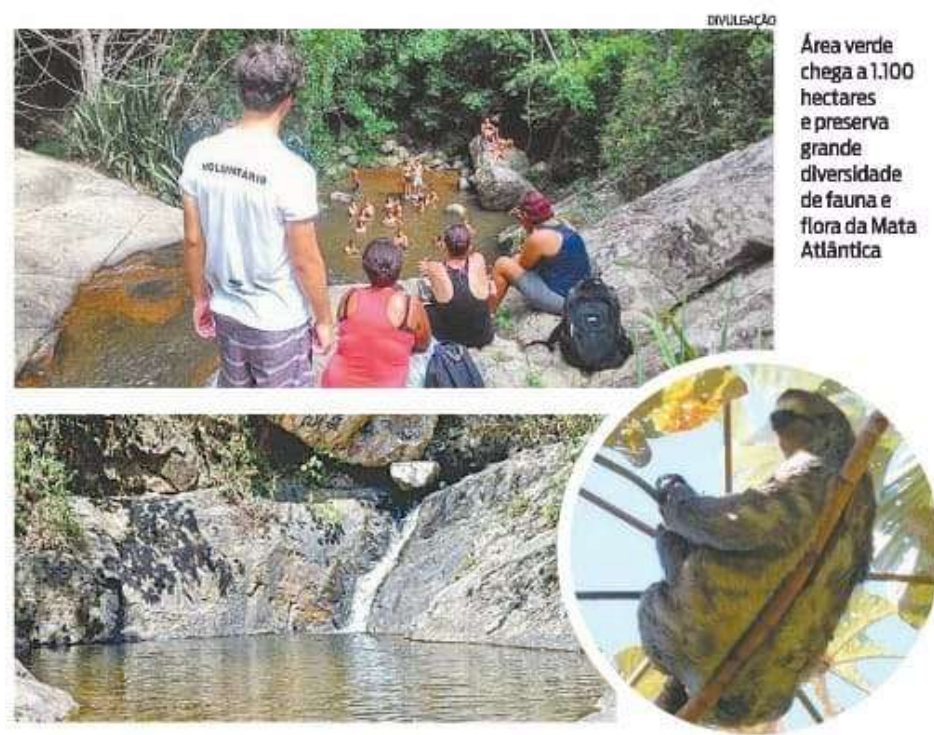

incentivo ao turismo local. "A expectativa é de que o parque seja mais valorizado e que as pessoas explorem tudo que ele tem a oferecer".

Com tanto potencial a expectativa é grande. "As pessoas văo ver a regiăo de forma diferente. Temos uma beleza natural funtástica etodos precisam conhecer", afirma Fernando Cid, secretário de Meio Ambiente de Nova Iguaçu.

Quem frequenta o local diz que a diversâo é garantida. "Há quase 10 anos orranizo caminas. Além de trage contuto com a contato com a natureza, é tudo de graça", diz o professor de Educaçăo Fisica, Luciano de Almeida Feitosa.

O Parque abre de $8 \mathrm{~h}$ às $16 \mathrm{~h}$. $O$ acesso mais fácil é pela Estrada da Cachoeira, em Mesquita Quem sai da estação de trem de Juscelino deve ir pela Av. Feliciano Sodré.

Fonte - Jornal O Dia, 10/09/2017.

\section{Atividades de pesquisa}

A UFRRJ já vem desenvolvendo pesquisas no PNMNI há algum tempo, há registros que nos anos 1970 pesquisadores ligados a essa instituição, ao analisarem fotos aéreas de Nova Iguaçu, constataram ocorrências de rochas vulcânicas que, dispostas de forma circular, cobriam uma extensa área da Serra de Madureira, no Maciço do Gericinó-Mendanha (VIEIRA; KLEIN, 2004). Na UC são desenvolvidas pesquisas em diferentes áreas do conhecimento, e variados tipos como artigos, Monografias de Graduação, Dissertações e Teses².

O campus Nova Iguaçu (IM-UFRRJ) fica bem próximo do PNMNI - cerca de $3 \mathrm{~km}$-, facilitando o desenvolvimento de ensino, de pesquisas e de extensão nesse território pelos pesquisadores dos cursos existentes, particularmente, Geografia, Pedagogia e Turismo. No recorte temporal de 2015 a 2019, no âmbito do curso de Geografia do IM-UFRRJ, foram realizadas: 01 dissertação de Mestrado; 01 pesquisa de Iniciação Científica 02 Monografias de Graduação; 02 capítulos de livro; 04 artigos publicados em revistas científicas; e 06 apresentações e publicações em eventos científicos nacionais e internacionais. Ressalte-se que aqui não foram apontadas as pesquisas em andamento. Observase assim, a vocação que o território do PNMNI tem para pesquisas, e se a escala for o Maciço Gericinó-Mendanha - onde o Parque está localizado - o quantitativo aumenta consideravelmente.

${ }^{2}$ Desde março de 2019 uma pesquisa de Iniciação Científica, financiada pela Fundação de Apoio à Pesquisa do Estado do Rio de Janeiro (FAPERJ) vem fazendo realizando o acervo do material científico produzido no/sobre o Parque, reunindo até o momento um quantitativo de aproximadamente 200 produções científicas-acadêmicas. 
Figura 6 - Trabalho de campo com a escola.

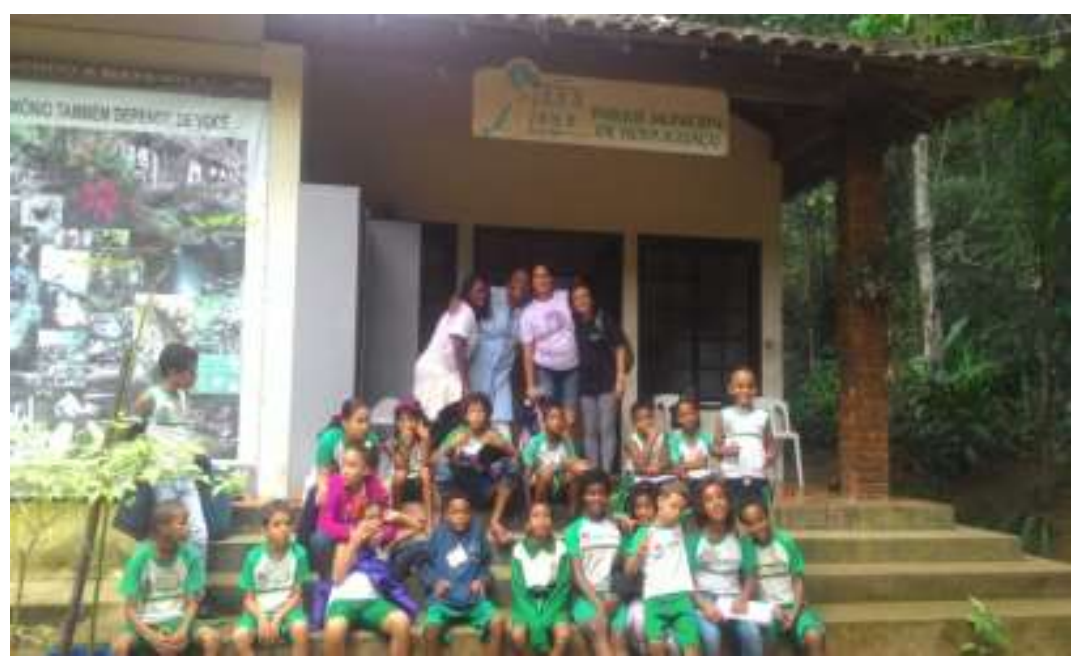

Fonte - a autora, 2016.

Na figura 6 acima, um grupo de alunos da Escola Municipal Ondina Co uto em um trabalho de campo após a realização da "Corrida de Orientação", uma atividade interdisciplinar integrante da pesquisa de Iniciação Científica, de um discente do curso de Geografia do IM-UFRRJ.

A ênf ase dada ao curso acima citado deve-se a fatos já esclarecidos anteriormente, entretanto, outras Instituições também se apropriam no referido espaço protegido para pesquisas. No recorte temporal de 2015 a 2019, foram realizadas um total de 25 pesquisas, entre teses, dissertações, Monografias de Especialização e de Conclusão de Curso de Graduação, artigos publicados em períodos e artigos apresentados e publicados em Anais de eventos acadêmicos-científicos.

\section{Atividades de Ensino}

O ensino superior faz uso do território do Parque para o desenvolvimento de diversas atividades de campo, especialmente cursos do IM-UFRRJ, como por exemplo o curso de Geografia - tanto na área física quanto na humana -, além das visitas programadas pelos cursos de Turismo, Pedagogia e História. No campo da Educação Básica, a Secretaria Municipal de Educação de Nova lguaçu desenvolve projetos de Educação Ambiental em parceria com o Parque. Além disso, alunos de um curso técnico em Meio Ambiente de uma escola da rede estadual também realiza atividades de ensino nessa UC.

Figura 7 - Trabalho de campo com a graduação em Geografia IM-UFRRJ.

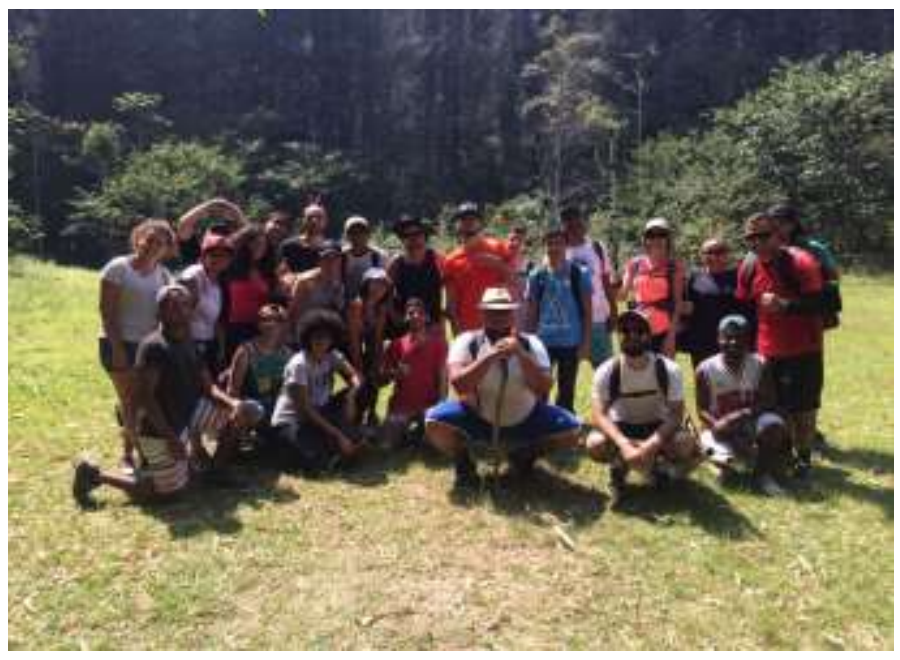

Fonte - Natalie Pereira, 2017

Caminhos de Geografia $\quad$ Uberlândia-MG $\quad$ v. 22, n. $82 \quad$ ago./2021 $\quad$ p. 89-101 Página 97


Conforme citado em momento anterior, cursos de Graduação do IM-UFRRJ realizam variadas atividades de campo no Parque. A figura 7 acima se refere a um trabalho de campo da disciplina Elementos de Geologia ministrada pela professora Laura Mendes, que semestralmente realiza trabalho de campo na UC com seus alunos, assim como outros docentes da Instituição.

No tocante às pesquisas, o PNMNI também é bastante procurado por docentes de diferentes Instituições, da Educação Básica, Graduação e Pós-Graduação, para realização de aulas de diferentes temáticas. Desta forma, ressaltamos que as vivências, interações, interpretações, reflexões e ações fazem desta UC um importante espaço educador para o desenvolvimento de atividades de Educação Ambiental.

\section{DISCUSSÃO}

\section{Parceria com a Universidade}

De acordo a pesquisa e outros trabalhos como Pimentel (2013), Pimentel, Magro e Silva Fil ho (2011), a parceria com a instituição universitária é algo muito promissor em um Parque. Atividades de ensino, pesquisas e de extensão contribuem muito para o uso público. Concordamos com Pimentel (2013) ao afirmar que a atuação das instituições universitárias em Parques é muito relevante para a geração de dados sobre ecologia e biodiversidade, acrescentamos que essa atuação é fundamental para a gestão do uso público.

Dentre os objetivos do SNUC, observa-se: "proporcionar meios e incentivos para atividades de pesquisa científica, estudos e monitoramento ambiental" (Artigo 4ำ, inciso X). Em consonância com essa legislação, a questão científica também é um dos objetivos da criação do PNMNI, no Plano de Manejo (página 9) consta: “(...) além dos objetivos básicos da preservação do meio ambiente, possibilitará a implementação de diversas pesquisas técnico-científicas acerca dos aspectos naturais, históricos e culturais".

Há um bom diálogo entre a gestão do PNMNI e pesquisadores interessados em desenvolver pesquisas nesse território, pela diversidade de temáticas presentes é considerado um "laboratório a céu aberto", com grande vocação para atividades de ensino, de pesquisa e de extensão.

\section{Gestão Integrada e Participativa: proposta para a criação do Mosaico Maciço Gericinó- Mendanha}

A gestão integrada e participativa, assim como parcerias com instituições de pesquisa, também pode trazer muitos benefícios, segundo Soares, Bensusan e Ferreira Neto (2004, p. 32), para que isso ocorra "(...) é necessário que haja disposição dos diferentes atores envolvidos com a área para debater questões polêmicas e difíceis, e dividir responsabilidades”. Para tal, há necessidade de capacitação, de diálogo e vontade política. O PNMNI está localizado em dois municípios, no entanto, apenas um destes é responsável pela gestão, além disso, no maciço Gericinó-Mendanha estão dispostas cinco UC de categorias diferentes e esferas governamentais também distintas.

A figura 8, a seguir, nos mostra as diferentes UC que estão dispostas no maciço Gericinó-Mendanha. Entretanto, não há um trabalho coletivo entre os gestores, se houvesse uma interação, é possível que problemas como o combate aos incêndios na APA Gericinó-Mendanha - nos limites do PNMNI - não fossem controlados apenas pelos funcionários dessa UC, o que torna o serviço extremamente difícil. Assim, é pertinente a criação do "Mosaico Maciço Gericinó-Mendanha". 
Figura 8 - Unidades de Conservação localizadas no Maciço Gericinó-Mendanha.

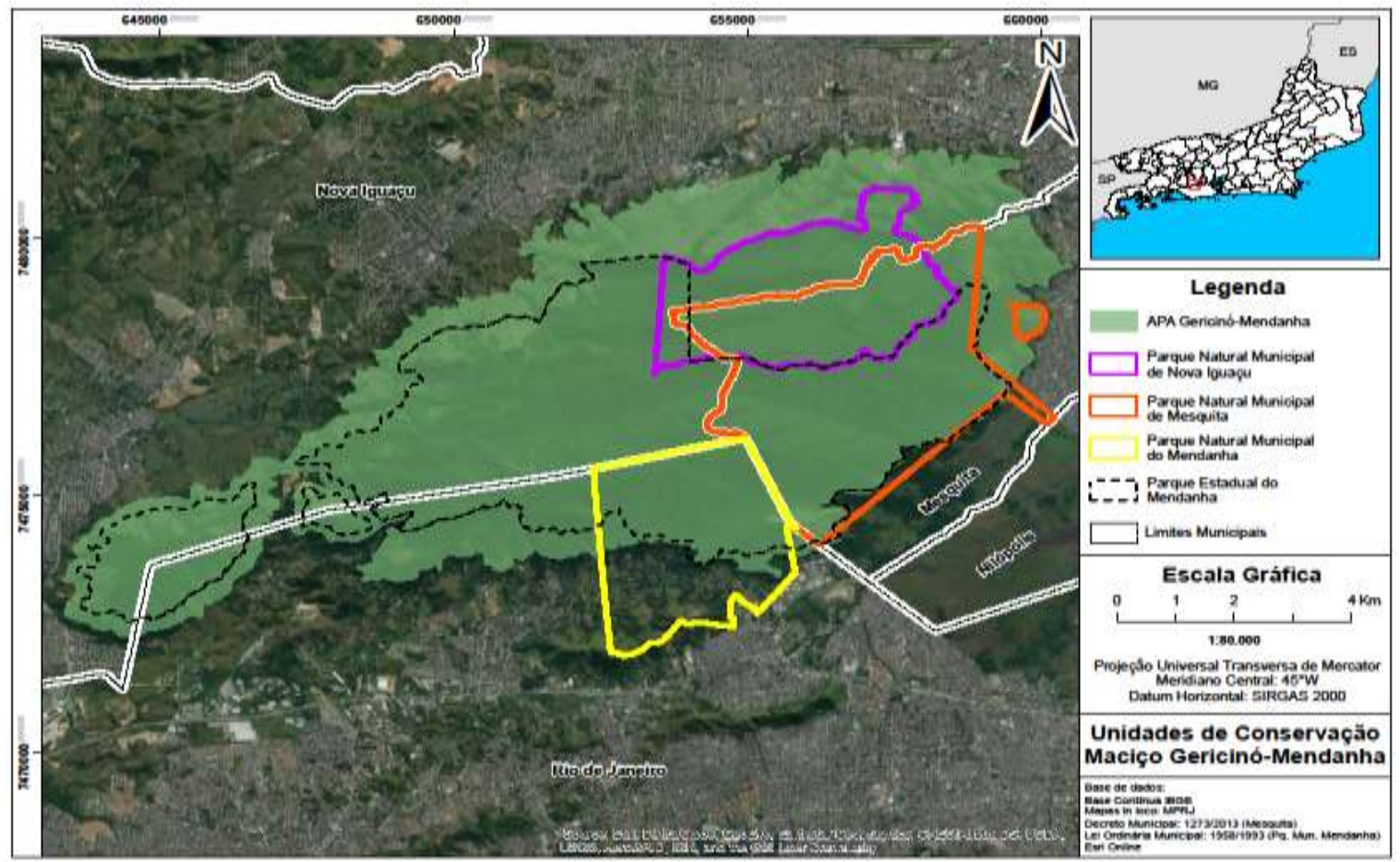

Fonte - Queiroz, 2018.

Um trabalho conjunto entre os gestores das diferentes UC desse maciço poderia ajudar a mapear os problemas socioambientais para que, coletivamente, houvessem reflexões sobre ações integradas. Isso, possivelmente, melhoraria a eficiência na fiscalização e no monitoramento do espaço.

O Mosaico Carioca, criado através da portaria 245, de 11 de julho de 2011, inclui a APA GericinóMendanha, entretanto, apesar do PNMNI estar sobreposto nesta APA não há um diálogo ef etivo. E o Parque não foi convidado a compor esse mosaico, isso acaba ferindo a legislação (SNUC), quando se refere aos mosaicos ressalta que a gestão deve ser feita de maneira integrada, pois no capítulo IV, artigo 26, consta:

Quando existir um conjunto de unidades de conservação de catego rias diferentes ou não, próximas, justapostas ou sobrepostas, e outras áreas protegidas públicas ou privadas, constituindo um mosaico, a gestão do conjunto deverá ser feita de forma integrada e participativa, considerando-se os seus distintos objetivos de conservação, de forma a compatibilizar a presença da biodiversidade, a valorização da sociodiversidade e o desenvolvimento sustentável no contexto regional. (Grifos nossos).

Deste modo, observamos que a legislação existe, mas a vontade política ainda é frágil. Acredita-se que o mosaico seria muito benéfico porque é um instrumento de gestão e ordenamento territorial que contribui para a valorização das características e da identidade da região, bem como viabilizaria a implantação de corredores ecológicos entre as diferentes UC, partindo da premissa de que as espécies, ecossistemas e paisagens não respeitam as fronteiras políticas (BENSUSAN, 2014). Além disso, os mosaicos incorporam processos sociais, econômicos e políticos ao bioma, de modo a planejar paisagens mais sadias (PRIMACK; RODRIGUES, 2001).

Diante do exposto, podemos verificar que existem alguns caminhos que podem direcionar para a consolidação do uso público no PNMNI, no sentido de equacionar a preservação da biodiversid ade e a inserção social de forma ordenada, ancorada na participação, especialmente as pessoas que

$\begin{array}{llllll}\text { Caminhos de Geografia } & \text { Uberlândia-MG } & \text { v. 22, n. 82 } & \text { ago./2021 } & \text { p. 89-101 } & \text { Página } 99\end{array}$


moram no entorno, e isso precisa de um trabalho de informação/sensibilização/formação. Para que isso ocorra, acredita-se no potencial das parcerias com as universidades e outras instituições, bem como maiores investimentos por parte das diferentes esferas do poder público.

\section{CONSIDERAÇÕES FINAIS}

Através das atividades que foram realizadas no desenvolvimento da pesquisa, é possível afirmar que, apesar dos obstáculos existentes para a consolidação do uso público com condições de conciliar a conservação ambiental com as atividades humanas em parques naturais, existem caminhos possíveis para vencê-los. Exige muito comprometimento e vontade política, e desta forma, representam grandes desafios porque envolve pessoas com diferentes percepções, saberes e interesses.

A pesquisa também revelou o potencial do voluntariado ambiental para os Parques, uma prática que vem crescendo nas UC brasileiras nos últimos anos. É um compromisso social que busca tornar o cidadão sensibilizado, apto a atuar principalmente no coletivo. Durante a pesquisa, foi elaborado um projeto-piloto de voluntariado com duração de seis meses, com o seu término em fevereiro de 2017, os voluntários se fortaleceram e, atualmente, há um grupo de voluntários atuando no PNMNI.

Um fator de grande importância e interesse para o uso público em Parques são as parcerias. Pimentel (2013) aponta várias atividades que contribuem para a consolidação desse uso público através das parcerias, principalmente, com as universidades. Algumas instituições universitárias, principalmente as públicas sediadas no estado do Rio de Janeiro vêm realizando atividades de ensino, pesquisa e extensão no PNMNI, com resultados bem expressivos. Ressalte-se a importância dessas atividades que muito podem contribuir para o uso público no Parque, o que impacta positivamente tanto a população do entorno quanto os usuários-visitantes.

Uma das propostas da pesquisa, a Gestão Integrada e Participativa, é a criação do Mosaico Maciço Gericinó-Mendanha, tendo em vista que o mosaico pode ser institucionalizado a partir das UC dispostas no referido maciço, conforme apresenta a figura 8. Este modelo de gestão tem entre seus objetivos integrar as atividades desenvolvidas pelas UC. Pereira e Loureiro (2014, p. 7), baseados no Artigo 26 da Lei $n^{\circ}$ 9895/2000, apontam que os mosaicos "(...) têm a intenção de ampliar os limites dos limites das UC, compatibilizando a presença da biodiversidade, a valorização da sociobiodiversidade, e o desenvolvimento sustentável no contexto regional". O que está em consonância com a gestão do uso público eficiente no território. Cabe ressaltar que os caminhos que podem nos levar a essa consolidação exigem esforços, tanto do poder público quanto da sociedade civil.

\section{AGRADECIMENTOS}

Ao Programa de Pós Graduação em Geografia da Universidade Federal Fluminense; ao Departamento de Geografia do Instituto Multidisciplinar/Universidade Federal Rural do Rio de Janeiro; aos discentes dos Cursos de Geografia e Pedagogigia do IM-UFRRJ e voluntários do PNMNI; ao Gestor do PNMNI, senhor Edgar Martins; à SEMADETUR/Nova Iguaçu-RJ.

\section{REFERÊNCIAS BIBLIOGRÁFICAS}

AMADOR, A.B.; PALMA, L.M. Dez anos do programa de voluntários do Parque Nacional da Tijuca. In: Uso Público em Unidades de Conservação: planejamento, turismo, lazer, educação e impactos. Artigos do $1^{\circ}$ e $2^{\circ}$ Encontros Fluminenses - 2013 e 2015. Niterói: Ed. Alternativa, 2015. https://doi.org/10.47977/2318-2148.2013.v1n2p14

BENSUSAN, N. Conservação da biodiversidade em áreas protegidas. Rio de Janeiro: Editora FGV, 2014

$\begin{array}{lllll}\text { Caminhos de Geografia } & \text { Uberlândia-MG } & \text { v. 22, n. } 82 & \text { ago./2021 } & \text { p. 89-101 }\end{array}$


BRASIL. Sistema Nacional de Unidades de Conservação. Disponível em: <http://www.mma.gov.br/areas-protegidas/sistema-nacional-de-ucs-snuc>. Acessado em: $31 / 03 / 2016$

CUNHA, L.H; COELHO, M.C.N. Política e Gestão Ambiental. In: CUNHA, S.B.C.; GUERRA, A.J.T. (Orgs.). A questão ambiental: diferentes abordagens. Rio de Janeiro: Bertrand Brasil, 2007.

DOUROJEANNI, M.J.Vontade política para estabelecer e manejar parques. In: TERBORGH, J.et al. (Org.). Tornando os parques eficientes: estratégias para a conservação da natureza nos trópicos. Curitiba: Editora da UFPR, 2002

DUARTE, P.A. História ambiental de uma unidade de conservação: o Parque Municipal de Nova Iguaçu-RJ. Dissertação (Mestrado). UERJ, 2010.

Ministério do Meio Ambiente. Planejamento e Operação de Programas de Voluntariado em Unidades de Conservação. Brasília: MMA/SBF/DAP, 2002.

MONIZ, A.L.F.; GÜNTHER, H. Voluntariado Ambiental: um estudo exploratório. In:Psico. Vol. 42, no $1,2011$.

MORAES, A.C.R. Meio Ambiente e Ciências Humanas, 4a edição ampliada. São Paulo: Annablume, 2005.

PEREIRA, D.R.; LOUREIRO, C.F.B. A gestão integrada dos mosaicos de áreas protegidas como ferramenta para o desenvolvimento da cultura da participação social e da sustentabilidade local. In: Anais do X Congresso Nacional de Excelência em Gestão, Niteroi, 2014.

PIMENTEL, D. S. Parcerias para a gestão do uso público em parques. In: Anais - Uso Público em Unidades de Conservação, n. 1, v.1, Niterói, 2013. https://doi.org/10.47977/23182148.2013.v1n1p27

PIMENTEL, D.S.; MAGRO, T.C; D.F, SILVA FILHO. Imagens da Conservação: em busca do apoio público para a gestão de unidades de conservação. In: Teoria e Sociedade. n. 19, 2011.

PRIMACK, R.B.; RODRIGUES, E. Biologia da Conservação. Londrina: Editora Planta, 2001

QUEIROZ, E.D. Uso Público no Parque Natural Municipal de Nova Iguaçu-RJ: trilhando entre possibilidades e dificuldades. Tese de Doutorado em Geografia. Niterói: UFF, 2018.

RODRIGUES, C.G.O.; IRVING, M. A.; DRUMMOND, J. A. Da Visita e do Turismo: uma reflexão sobre o Uso Público em Parques Nacionais. In: Encontro Nacional de Turismo com Base Local, Niterói. Anais... UFF, 2010.

SELLI, L.; GARRAFA, V. Bioética, solidariedade crítica e voluntariado orgânico. In:Revista de Saúde Pública. V.39, № 3, 2005. https://doi.org/10.1590/S0034-89102005000300020

SOARES, M.C.C., BENSUSAN, N., FERREIRA NETO, P.S. Entorno das Unidades de Conservação: estudo de experiências com UCs de Proteção Integral. Rio de Janeiro: FUNBIO, 2002.

VALLEJO, L.R. Políticas públicas e conservação ambiental: territorialidades em conflitos nos parques estaduais da Ilha Grande, da Serra da Tiririca e do Desengano (RJ). Tese (Doutorado). Universidade Federal Fluminense, 2005.

VIEIRA, A.C.; KLEIN, V.C. Vulcão de Nova Iguaçu, o vulcão brasileiro. CREA-RJ, 2004.

Recebido em:29/06/2020

Aceito para publicação em:06/04/2021 